\title{
Transactions
}

Cite this: Dalton Trans., 2011, 40, 1061

wWW.rsc.org/dalton

PAPER

\section{Mapping the potential energy surfaces for ring-closing metathesis reactions of prototypical dienes by electronic structure calculations $\uparrow$}

\author{
Ian H. Hillier, ${ }^{* a}$ Shanthi Pandian,,$^{a}$ Jonathan M. Percy*b and Mark A. Vincent ${ }^{a}$
}

Received 30th September 2010, Accepted 24th November 2010

DOI: $10.1039 / \mathrm{codt01314e}$

\begin{abstract}
The potential energy surfaces for ring-closing metathesis reactions of a series of simple $\alpha, \omega$-dienes which lead to 5-10 membered ring products, have been explored using density functional theory methods. We have investigated both the conformational aspects of the hydrocarbon chain during the course of the reactions, as well as the stationary structures on the corresponding potential energy surfaces. Extensive conformational searches reveal that the reaction proceeds via the conformation that would be expected for the cycloalkene product, though most unexpectedly, cyclohexene forms via complexes in boat-like conformations. The M06-L density functional has been used to map out the potential energy surfaces, and has identified metallocyclobutane fragmentation as being generally the highest barrier along the pathway. The structural variations along the pathway have been discussed for the reactant hydrocarbons of differing chain length to identify points at which cyclisation events may begin to affect reaction rates. Our study provides an excellent starting point from which to begin to learn about the way RCM reaction outcomes are controlled by diene structure.
\end{abstract}

\section{Introduction}

The importance of alkene metathesis reactions has grown spectacularly since well defined and air stable metal-alkylidene catalysts 1a-1c became commercially available. ${ }^{1}$ The closure of highlyfunctionalised carbocycles and heterocycles of a wide range of sizes can be achieved under mild conditions, and many groups have executed elegant syntheses of complex natural products based on ring-closing metathesis (RCM) reactions, ${ }^{2}$ some of which use ingenious control or editing strategies. ${ }^{3}$ However, the excitement generated by the synthetic chemistry has stimulated remarkably few detailed quantitative studies of RCM chemistry. ${ }^{4}$ The Boehringer-Ingelheim ${ }^{5,6}$ group has rigorously explored a macrocyclisation by RCM as part of a process chemistry optimisation, while Monfette and Fogg ${ }^{7}$ recently reviewed the influence of thermodynamic control on RCM outcomes. In a series of elegant experiments, Metzger and co-workers have recently used ESI-MS to compare the stabilities of various ions on the RCM pathway of simple dienes catalysed by $\mathbf{1 a}$ in the mass spectrometer, ${ }^{8}$ while Piers

${ }^{a}$ School of Chemistry, University of Manchester, Oxford Road, Manchester, UK M13 9PL. E-mail: ian.hillier@manchester.ac.uk; Fax: +44 161275 4734; Tel: +441612754687

${ }^{b}$ West CHEM, Department of Pure and Applied Chemistry, Thomas Graham Building, 295 Cathedral Street, Glasgow, G1 1XL.E-mail:jonathan.percy@ strath.ac.uk; Fax: +44 141548 4822; Tel: +44 1415484398

$\dagger$ Electronic supplementary information (ESI) available: Cartesian coordinates and energies for the stationary structures on the RCM potential energy surfaces, for the lowest energy conformers and more. See DOI: $10.1039 / \mathrm{c} 0 \mathrm{dt} 01314 \mathrm{e}$

¥Universität Heidelberg, Anorganisch-Chemisches Institut, INF 270, 69120 Heidelberg, Germany. and van der Eide have identified a series of key intermediates using low temperature NMR., ${ }^{9,10}$ There have been many computational studies; for example, the strength of ligand binding, ${ }^{11}$ and the mode of coordination (bottom or side bound) have been explored extensively. ${ }^{12-15}$ Complex systems of special synthetic interest, ${ }^{16,17}$ are also described but studies of full systems ${ }^{18,19}$ of general interest and importance are rare. ${ }^{20}$ Despite all this activity, systematic studies of the relationship between structure and reactivity remain few and far between. Our solution experimental work quantified the efficiency of formation of some substituted cyclooctenes by $\mathrm{RCM},{ }^{21}$ where we measured the first effective molarities for RCM reactions. We also showed that the medium-ring products formed directly from acyclic diene precursors without the detectable intermediacy of oligomeric species, suggesting strongly that we were following a kinetically-controlled process (meaning that the product formed arose from the fastest reaction), and not a de-oligomerisation via backbiting ${ }^{22}$ in which the most stable product formed. During the course of our work, we became aware that there was relatively little underpinning computational work dealing with the RCM of prototypical $\alpha, \omega$-dienes. We therefore now describe a computational study of the RCM reactions of simple $\alpha, \omega$-dienes, the prototypical RCM substrates, using density functional theory (DFT) methods, from which we can begin to learn about the way reaction outcomes are controlled by diene structure.

Scheme 1 shows a catalytic cycle and the potential complexity of the RCM reaction. Here methylidene 2 maintains the cycle after the first turnover of pre-catalyst, and the ability of this species to react with starting diene $\mathbf{3}$, cycloalkene product $\mathbf{4}$ and dimer $\mathbf{5}$ (the precursor to linear and cyclic oligomers) must be considered. In 


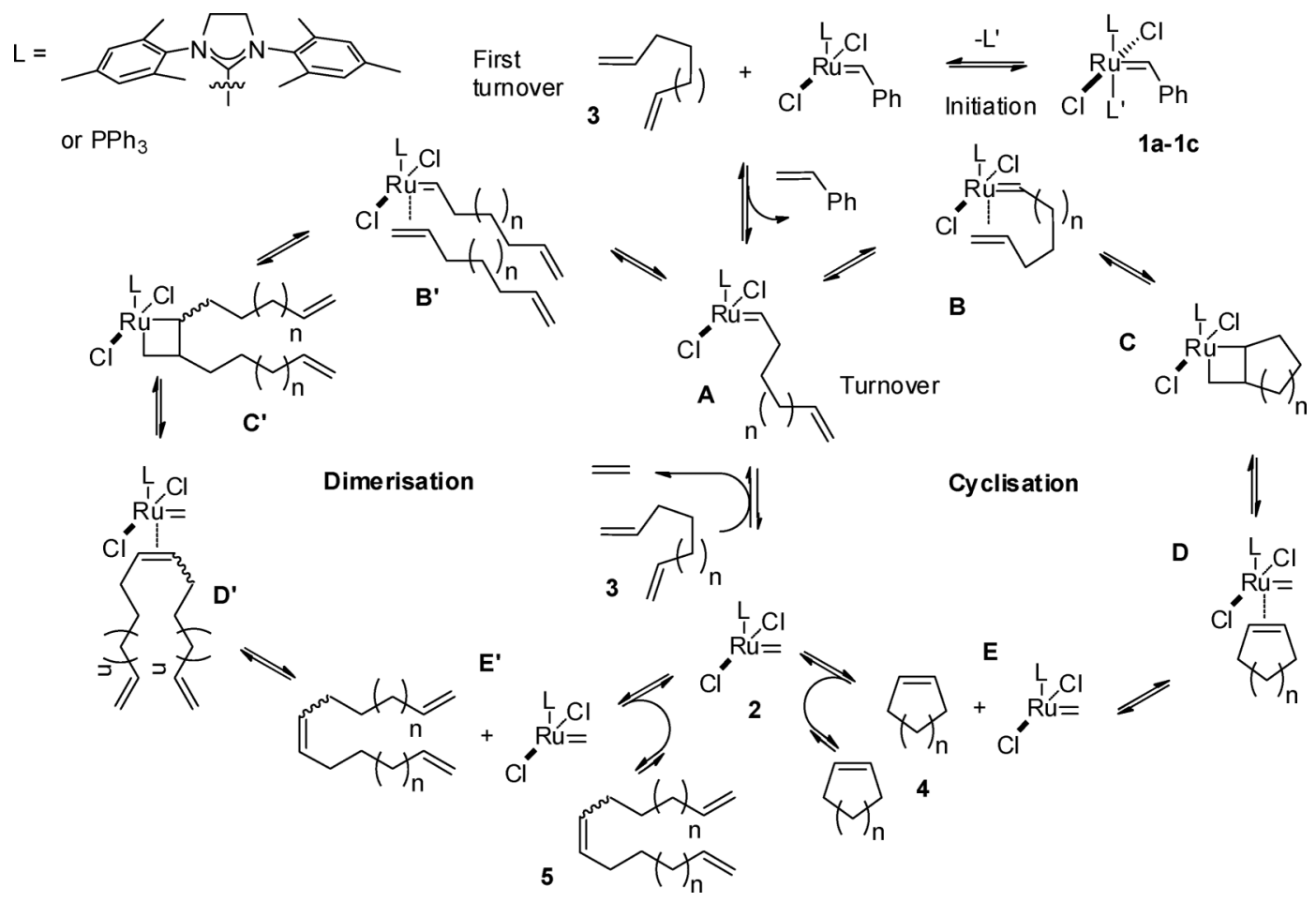

Scheme 1 Catalytic cycle showing RCM and dimerisation pathways and the important complexes.

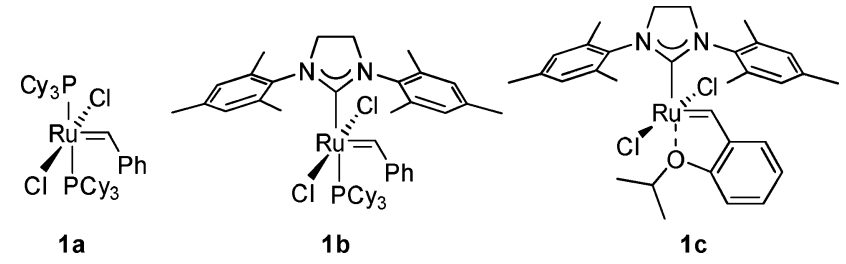

principle, all of these pathways are reversible and the reaction can be subject to thermodynamic control. The possibility of thermodynamic control must be considered very carefully because of the ability of the extremely effective and widely-used second generation Ru pre-catalyst $\mathbf{1 b}$ to react with disubstituted alkenes. ${ }^{23}$ If all the steps are reversible, product $\mathbf{4}$ or dimer $\mathbf{5}$ can re-enter the catalytic cycle and after equilibration, the product with the lowest free energy will dominate the reaction mixture.

The fastest reactions available to $\mathbf{2}$ are likely to be with the terminal alkenyl groups presented by the acyclic diene and linear dimer (and higher oligomer). ${ }^{24}$ The outcome of RCM carried out under kinetic control depends on the partitioning of alkylidene $\mathbf{A}$ between the $\eta^{2}$-complexes $\mathbf{B}$ and $\mathbf{B}^{\prime}$, and therefore on the relative rates and equilibrium constants for the pathways to $\mathbf{E}$ and $\mathbf{E}^{\prime}$. Kinetic control of this type of sequence is likely when the disubstituted alkene products re-enter the cycle slowly, either because of the pre-catalyst used, or because of features of the product structure. Understanding how structural changes and their effects on individual reaction steps affect overall rate or frequency of turnover represents a major challenge. In this manuscript, we focus on the events which define the cyclisation reaction, rather than the alkylidene transfer sequence from $\mathbf{3}$ to A (Scheme 1) which should be common to all the systems in the current study.
Almost all of the systems studied by synthetic chemists are highly functionalised. Ring-opening metathesis polymerization (ROMP) reactions of simple cycloalkenes have been well studied by polymer chemists and catalyst developers, ${ }^{25}$ but the reaction concentrations used are usually high and the data cannot tell us directly about RCM efficiency. We therefore decided to explore the RCM reactions of the simplest acyclic dienes because the outcomes could be related closely to thermodynamic changes. Simple alicyclic systems are fairly well defined conformationally, so we can make predictions about the conformations of the intermediate organometallic complexes and test these predictions using electronic structure calculations employing appropriate density functionals. We could then begin to understand RCM reaction efficiency; RCM reactions differ significantly in their geometries at critical stages from those of the cyclic ether and lactone-forming reactions upon which the literature dealing with intramolecularity is based ${ }^{26-28}$ so an accurate inventory of free energy changes throughout the RCM reaction as a function of ring size and molecular conformation could be extremely useful. This manuscript aims to lay a foundation for a better understanding of the thermodynamics of RCM, and the thermodynamic changes occurring inside the various compartments within the reaction. To achieve this end, we must consider the following issues; firstly, what is the conformation of the hydrocarbon chain on the potential energy surface (PES) of the reaction (Scheme 1)? In particular, is the conformation of the initial $\eta^{2}$-complex (B) maintained during the reaction? Secondly, what are the energetics of the various stationary structures (both minima and transition structures) on the PES, and how do the surfaces vary for different hydrocarbon chain lengths? The manuscript will not try to predict rate constants; this will be a goal of manuscripts in which we present reaction kinetic analysis. 
Table 1 Free energy changes ( $\mathrm{kcal} \mathrm{mol}^{-1}$, in dichloromethane) at the M06-L/B2 level, for the full reaction profiles based on the lowest energy conformers, and normalised to the sum of diene and methylidene (2) free energies

\begin{tabular}{lllllllll}
\hline Ring Size & Diene $+2^{a}$ & A & B & BC & C & CD & D & E $(\text { Cycloalkene }+2)^{a}$ \\
\hline 5 & 0 & -4.05 & -15.53 & -12.10 & -14.13 & -0.62 & -7.48 & -3.98 \\
$6^{b}$ & 0 & -4.54 & -11.13 & -8.67 & -14.75 & -3.92 & -9.27 & -8.06 \\
7 & 0 & -4.38 & -12.04 & -6.55 & -12.98 & -3.48 & -5.44 & -3.55 \\
8 & 0 & -4.30 & -9.45 & -4.07 & -8.96 & -1.86 & -5.07 & -1.27 \\
9 & 0 & -4.45 & -5.20 & 0.94 & -5.30 & 4.36 & -0.55 & 2.45 \\
10 & 0 & -3.98 & -8.42 & 0.07 & -4.14 & 1.68 & -3.81 & -0.27
\end{tabular}

${ }^{a}$ See Scheme $1{ }^{b}$ This represents the pathway through the lowest energy conformers for the 6-ring with change in conformation before metallocyclobutane fragmentation.

We have adopted the following computational strategy to address these questions.

\section{Computational strategy}

\section{Hydrocarbon conformation}

We propose to explore the conformational space available to the complexes of simple hydrocarbon dienes and the tensions and constraints created by coordination to the metal centre. We also wish to develop a set of robust templates (by this we mean a set of reliable starting conformations upon which more complicated synthetic architectures can be built) which can be used to further our understanding of the behaviour of more complex systems and upon which we can model substituent effects.

Given the length of the hydrocarbon chains being considered, it was necessary to carry out conformational searches to identify the lowest energy, or at least one of the lower energy conformers for reaction. The conformational space occupied by the cycloalkenes was searched using the Monte Carlo conformer distribution algorithm (cycloalkenes) in Spartan (MMFF94 forcefield). ${ }^{29}$ The conformational searches and preliminary location of energy minima were carried out using Spartan'06 ${ }^{30}$ or Spartan'08. ${ }^{31}$ For these calculations, the LACVP basis sets, which combine the 6-31G family of basis sets with a LANL2DZ effective core potential on atoms heavier than Ar, were employed. Promising conformations were optimized using the widely employed B3LYP density functional and the LACVP* basis (B3LYP/LACVP*); this combination of functional and small basis is probably adequate to study different hydrocarbon conformations and is necessary to allow for the evaluation of a range of different structures and the avoidance of bias.

Prior to the conformational search of hydrocarbons bound to $\mathrm{Ru}$, a pair of templates was generated from $\eta$-bound ethylene and the four membered metallocyclobutane (formed from this $\eta$ complex). ${ }^{32}$ The status and application of these templates will be discussed in more detail later. Starting $\eta^{2}$-complexes were built individually on the template, the tether conformation being matched to a metallocyclobutane conformer in each case. For each complex, the geometry was optimised at the B3LYP/LACVP* level. In this way, we arrived at a conformation for each hydrocarbon that seemed to be energetically accessible throughout the entire reaction sequence and we were also aware of significant alternative conformations. All the dienes used in our study were optimised with the hydrocarbon chain fully staggered; this conformation was confirmed as the lowest energy species using the equilibrium conformer algorithm implemented in the Spartan programmes.

\section{Electronic structure calculations of the PES}

We have previously ${ }^{33}$ used high level wavefunction calculations $(\operatorname{CCSD}(\mathrm{T}))$ on a model system ${ }^{34}$ to show that the ubiquitous B3LYP function is not sufficiently accurate for the calculation of the relative energies of the various structures on the PES (Scheme 1), whereas the newer M06 functionals (M06 and M06L) have the required accuracy. ${ }^{35-39}$ Gaussian $03^{40}$ was employed with a local implementation of the M06-L functional for the calculation of the stationary structures on the PES (Scheme 1). Two basis sets, B1 and B2, were employed, which were used previously. ${ }^{41}$ Basis $\mathrm{B} 1$ consisted of the effective core potential (ECP) and double zeta basis (LanL2DZ) on Ru (with an added f-function of exponent 0.5780 ), the $6-31 G^{*}$ basis on heavy atoms, and 6-31G on hydrogens. The larger basis, B2, consisted of the SDD ECP and corresponding basis set on $\mathrm{Ru}^{42}$ with the same f-function as $\mathrm{B} 1$, and with a $6-311 \mathrm{G}^{* *}$ basis on all other atoms. The stationary structures obtained with the small basis (B1) were characterized as minima or transition structures by calculation of the harmonic frequencies. Geometry optimization was further carried out using the larger basis (B2), starting with the B1 structures. There were normally only minor changes in the structures, and harmonic frequencies were therefore not computed. Thus, the electronic energies for the optimal B2 structures were corrected for thermodynamic effects (to give free energies) computed using the B1 structures and B1 basis. Finally, the effect of solvation was included by the use of the Conductorlike Polarizable Continuum Model (C-PCM) with a dielectric of 8.93 (dichloromethane). Unless otherwise stated, the energies for the species involved in the RCM reactions (Scheme 1) are free energies computed in this way. We now discuss the computational results of applying this strategy to the structures in Scheme 1.

\section{Computational results}

Table 1 summarizes the free energies (in dichloromethane) at the M06-L/B2 level, for the full reaction profiles based on the lowest energy conformers (vide infra for a discussion of the identification of these species), and normalised to the sum of diene and methylidene energies. The basis for the selection of these conformers will now be discussed. The structures of the species shown in Table 1 are in the Supplementary Information. $\dagger$ 


\section{Conformation of the initial $\eta^{2}$-complex (A)}

The 14 e propagating carbene complexes (A, Scheme 1) are formed by exergonic reactions between methylidene $\mathbf{2}$, which carries the catalytic cycle, and the corresponding dienes. The free energy difference is typically $4.3 \mathrm{kcal} \mathrm{mol}^{-1}$ (Table 1: the full range is $3.98-4.54 \mathrm{kcal} \mathrm{mol}^{-1}$ at $298 \mathrm{~K}$ ) so the equilibrium constant (K) for alkylidene transfer is $c a .1400$ in favour of the more substituted alkylidene species. This reaction releases ethene, which is often referred to as the driving force for alkene metathesis. Thus, even without the passage of ethene from solution to gas phase, the increase in the level of substitution of the alkylidene provides a substantial driving force for alkylidene transfer. ${ }^{43}$

In the $14 \mathrm{e}$ alkylidene complexes (A) the orientation of the $\mathrm{Ru}=\mathrm{CH}$ bond causes the hydrocarbon chain to project into free space, which brings the alkylidene proton into close contact with the $\mathrm{N}-\mathrm{C}$ (aryl) carbon in the propagating carbene complexes (Fig. 1) This H … C contact lay between 2.39 and $2.42 \AA$ (M06$\mathrm{L} / \mathrm{B} 2$ ) in all cases and thus might be expected to result in an attractive interaction, which would be correctly modelled by the M06 functional, but not by B3LYP. ${ }^{44}$

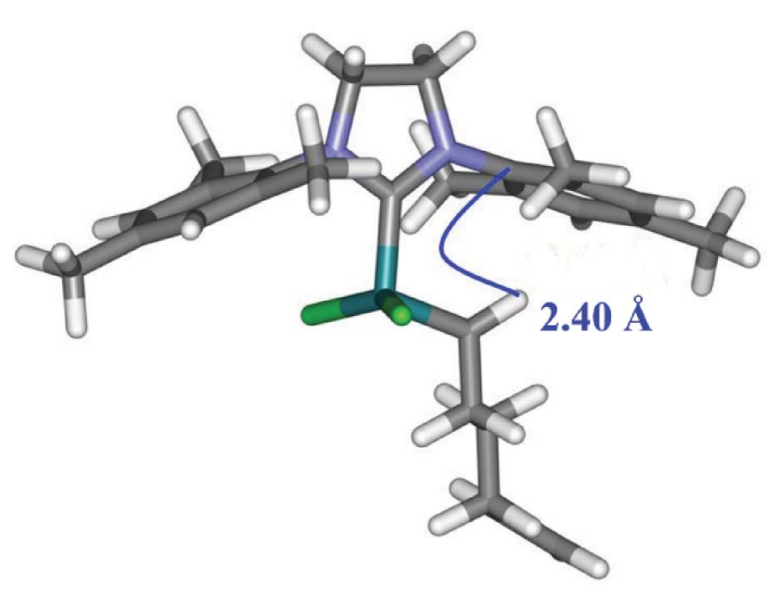

Fig. 1 The 14e alkylidene derived from 1,6-heptadiene (geometry optimised at M06-L/B2 level of theory) highlighting the short $\mathrm{N}(\mathrm{Ar}) \mathrm{C} \cdots \mathrm{H}-\mathrm{C}=\mathrm{Ru}$ contact.

To investigate this $\mathrm{H} \cdots \mathrm{C}($ aryl) interaction further, the interaction energy of a complex between methane and 1-amino2,4,6-trimethylbenzene (mesitylamine) (Fig. 2) having an $\mathrm{H}$... C distance of $2.39 \AA$ was evaluated. The interaction was predicted to be attractive (by $1.74 \mathrm{kcal} \mathrm{mol}^{-1}$ ) using the M06-L functional, but was repulsive (by $1.36 \mathrm{kcal} \mathrm{mol}^{-1}$ ) when B3LYP was used.

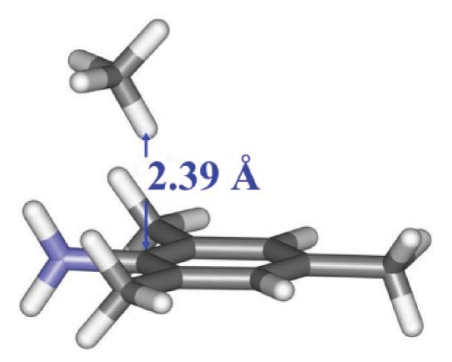

Fig. 2 Complex between methane and 1-amino-2,4,6-trimethylbenzene modelling the $\mathrm{H} \cdots \mathrm{C}($ aryl $)$ interaction identified in Fig. 1 .

\section{Conformation of the reactive $\eta^{2}$-complex (B)}

The next step is the formation of the $\eta^{2}$-complex (B), in which the double bonds, $\mathrm{C}=\mathrm{C}$ and $\mathrm{Ru}=\mathrm{C}$, are brought into close proximity. The conformational aspects of this interaction were investigated using the $\eta^{2}$-complex template 6 (Fig. 3). Straub explored $\mathbf{6 b}$ and the related structures $\mathbf{6 a}, \mathbf{6 c}$ and $\mathbf{6 d}$ and showed that the reactive alignment $\mathbf{6 b}$ of alkene and alkylidene was favoured by the presence of the N-heterocyclic carbene (NHC) ligand used in this study, the minimum being only $0.05 \mathrm{kcal} \mathrm{mol}^{-1}$ above the metallocycle (B3LYP/LACV3P**+//B3LYP/LACVP*).

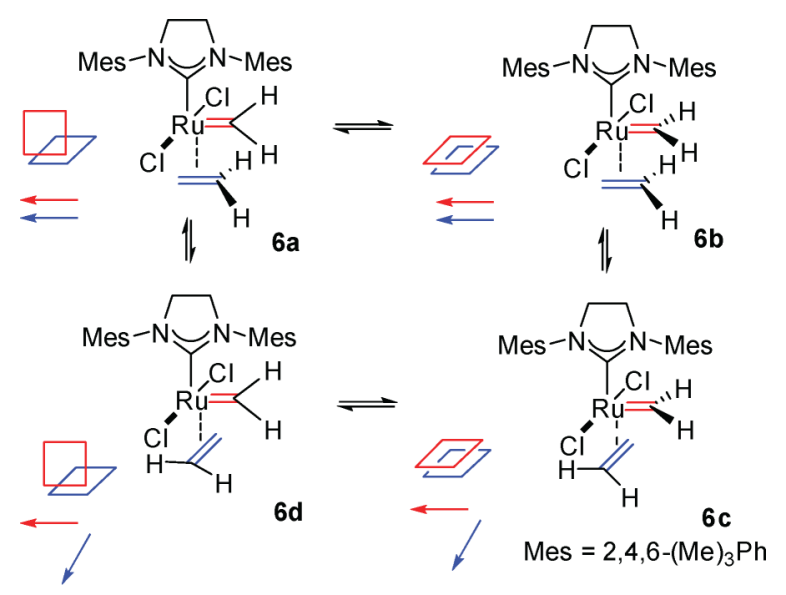

Fig. 3 The conformational possibilities for bottom-bound $\eta^{2}$-complex 6 . The arrows refer to the $\mathrm{C}-\mathrm{C} \sigma$-bond directions and the open parallelograms to the alkene and alkylidene $\sigma$-planes.

We optimised this template using B3LYP/LACVP* and B3LYP/B2. With the smaller basis (LACVP*), the structure was a minimum, but the metallocyclobutane was formed during optimisation with the higher basis. Further work showed that the stability of the $\eta^{2}$-complex in the reactive conformation is dependent on the basis sets used. Thus, removal of the f-functions from the B1 and B2 basis sets followed by optimisation revealed the $\eta^{2}$-complex to be a stable minimum. The $\eta^{2}$-complex was also a minimum when the M06-L functional was used (LACVP* or B2 basis), but the surrounding energy surface was very flat. On increasing the basis set from one to two f-functions on $\mathrm{Ru}$ and using a $6-311 \mathrm{G}(2 \mathrm{~d}, 2 \mathrm{p})$ basis on the other atoms, the $\eta^{2}$-complex collapsed to the metallocyclobutane. It would thus seem that this $\eta^{2}$-complex is only stable in the aligned and reactive conformation because of a basis set effect.

The addition of a hydrocarbon tether changes the way that the alkene and alkylidene bonds align and introduces conformational complexity. The four possible conformers (7a-7d, Fig. 4), corresponding to (6a-6d, Fig. 3) were then examined explicitly. We built models in which the $\eta^{2}$-coordinated alkene ligand and/or the alkylidene $\mathrm{Ru}=\mathrm{C}$ bond were turned through $90^{\circ}$ to correspond to these alternative states, but they turned back to $\mathbf{7 b}$ during optimisation at the B3LYP/B1 level.

This outcome is consistent with the known tendency of cyclopentanoids to populate envelope conformations, involving some eclipsing of adjacent bonds. ${ }^{45}$ The parallel aligned conformer represented by $\mathbf{7 b}$ therefore anticipates an envelope conformation whereas the orthogonal conformers $\mathbf{7} \mathbf{c}$ and $\mathbf{7 d}$ would seem difficult to populate within a ring of this size. 


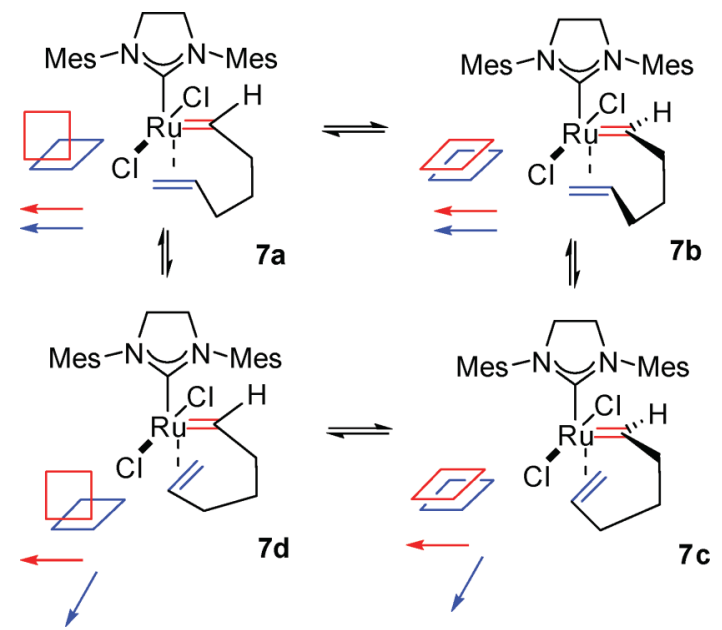

Fig. 4 The conformational possibilities for bottom-bound cyclic $\eta^{2}$-complex 7. The arrows refer to the alkene $\mathrm{C}-\mathrm{C} \sigma$-bond directions and the open parallelograms to the alkene and alkylidene $\sigma$-planes.

It is interesting to compare structure $\mathbf{7 b}$ with $\mathbf{8}$, obtained by Adlhart and $\mathrm{Chen}^{46}$ during their investigation of the ring-opening of norbornene.

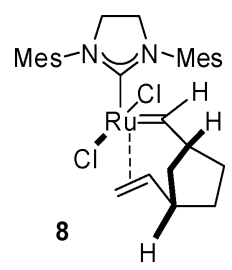

The turned alkylidene structure found in $\mathbf{8}$ (and like 7a) is usually favourable for species more substituted than methylidene $\mathbf{2}$, the $\mathrm{C}-\mathrm{C}$ and $\mathrm{Ru}-\mathrm{Cl}$ bonds becoming eclipsed when a hydrogen is replaced, and an allylic proton encroaches within van der Waals contact of the chlorine ligand in the frontal hemisphere. However, coordination of the $\omega$-alkene (in $7 \mathbf{b}$ ) brings the two $\pi$-bonds into alignment ready for metallocyclobutanation. The bicyclic nature of Adlhart and Chen's structure 8 allows a pair of eclipsed and pseudo-axial bonds to converge spatially, reducing the effective length of the tether. The disposition of this system to adopt the turned structure is entirely consistent with the high reactivity of norbornene ring towards ring-opening, ROMP and tandem ring opening/cross-metathesis reactions being well known for this and related substrates. ${ }^{47}$

We found two distinct aligned starting cyclic $\eta^{2}$-complexes for $\mathbf{7 b}$, so tethering allows the population of a productive conformation which can progress to the transition structure without conformational change, and imposes a significant $\left(\Delta G^{\ddagger}=3.4\right.$ $\mathrm{kcal} \mathrm{mol}^{-1}$, Table 1) barrier to metallocyclobutanation (vide infra). There is a significant degree of twisting of the $\mathrm{Ru}=\mathrm{C}$ alkylidene plane $\left(\mathrm{H}-\mathrm{C}=\mathrm{Ru}-\mathrm{Cl}\right.$ dihedral angle $\left.=24^{\circ}\right)$ in the lower energy of the two conformers (Fig. 5a), the hydrocarbon chain being chairlike in this complex. One allylic proton points in towards a chlorine atom in the lower energy conformer and the interatomic distance is just less than the sum of the van der Waals radii at $2.63 \AA$. In the higher energy boat-like conformer (Fig. 5b), the non-allylic methylene is folded in, so that one of the protons approaches to within $2.55 \AA$ of a chlorine ligand and the alkylidene plane is

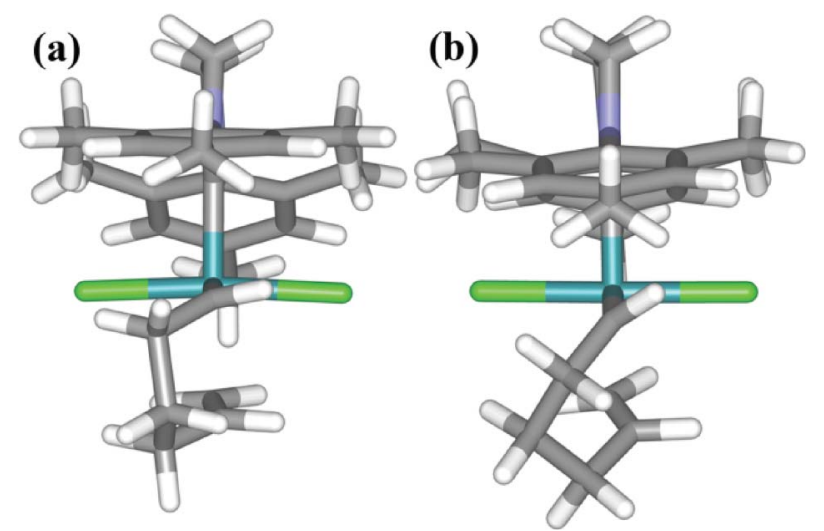

Fig. 5 Conformers found for $\mathbf{7 b}$ showing twisting of the alkylidene plane; (a) lower energy chair and (b) higher energy boat.

twisted by $41^{\circ}$ which represents a large distortion away from the expected geometry.

The chair-like conformer series was selected for optimisation with the M06-L functional and B2 basis; Fig. 6 overlays B3LYP (blue) and M06-L (red) structures and illustrates the different ligand geometries predicted.

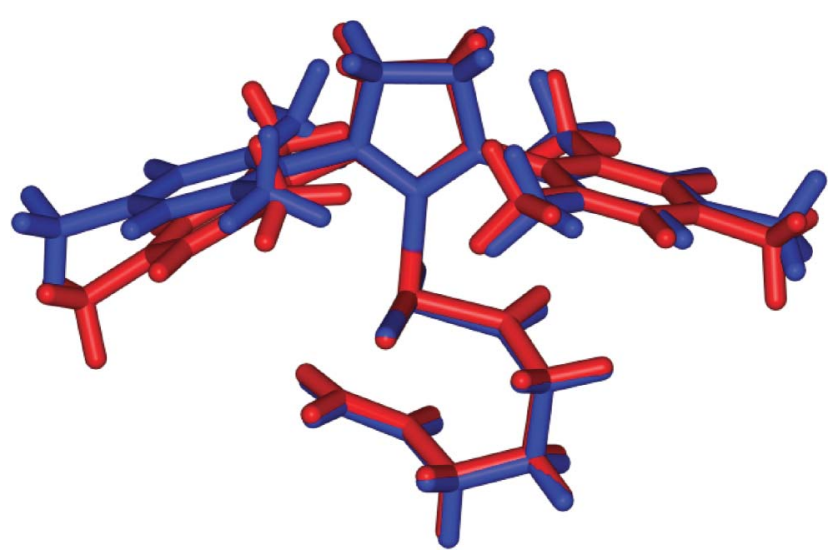

Fig. 6 Overlaid B3LYP/LACVP* (blue) and M06-L/B2 (red) structures calculated for $\mathbf{7 b}$ (low energy conformer).

The main significant difference in the geometries lies in the angle between the planes of the arene rings in the NHC ligand, the M06-L functional making this angle more acute. The change in the position of the arene which sits over the alkylidene $(\mathrm{Ru}=\mathrm{C})$ bond is minimal whereas the left-hand arene changes position, screening the $\mathrm{Ru}$ atom more effectively than in the B3LYP structure.

Cyclohexene exists in a half-chair form in solution, and conformational inversion occurs via a boat transition state with a barrier of $5.3 \mathrm{kcal} \mathrm{mol}^{-1} .{ }^{48,49}$ In the initial search (B3LYP/LACVP*), the lower energy conformer in the initial cyclic $\eta^{2}$-complex was boatlike and $1.3 \mathrm{kcal} \mathrm{mol}^{-1}$ lower in (gas phase electronic) energy than the best half-chair complex. The boat-like conformer became still more stable (by $2.0 \mathrm{kcal} \mathrm{mol}^{-1}$ ) than the half-chair when the free energies were calculated (M06-L/B2, dichloromethane solution). We also found a second diastereoisomeric half-chair conformer, though this lay $3.6 \mathrm{kcal} \mathrm{mol}^{-1}$ above the boat-like structure (M06-L/B2, dichloromethane solution) (see the Supplementary Information for illustrations). 
The alkylidene group, in the lower energy boat-like conformation, has the $\mathrm{H}$ tilted towards the mesitylene ring $\left(12^{\circ}\right)$, whilst the half-chair conformation has this hydrogen atom pointing away from the mesitylene moiety $\left(12^{\circ}\right)$. The $\mathrm{CH}_{2}-\mathrm{CH}_{2}$ dihedral in the boat-like tether is twisted by $35^{\circ}$ to minimise the eclipsing interaction between adjacent methylene groups with the closest approach between protons being $2.33 \AA$. These results are most unexpected because they show that the anticipated half-chair conformer is the less accessible species, with the boat-like conformer representing the lowest energy entry point to the cycle. Both complexes have essentially the same geometry of alkene coordination with both $\mathrm{C}=\mathrm{C}$ bond distances being $1.37 \AA$ and the shortest $\mathrm{C} \cdots \mathrm{Ru}$ bonds being 2.30 and $2.27 \AA$ for boat and half chair conformers, respectively. The two complexes contain a similar number of short $(<2.4 \AA) \mathrm{H} \cdots \mathrm{H}$ contacts. The half-chair also has the shortest $\mathrm{C}-\mathrm{H} \cdots \mathrm{C}(\mathrm{Ar})$ contact at $2.64 \AA$, leading to a favourable $\mathrm{H} \cdots \pi$ interaction.

We did not carry out extensive conformational searching for the initial $\eta^{2}$-complexes for the seven to nine membered rings because of the emergence of a pattern in which the metallocyclobutane was the lowest point on the energy surface, and its fragmentation the highest barrier, and in which the product $\eta^{2}$-complex was a reliable guide to low energy species on the surface (vide infra). However, the initial $\eta^{2}$-complex and not the metallocyclobutane is the lowest energy species (by more than $4 \mathrm{kcal} \mathrm{mol}^{-1}$ ) for $Z$ cyclodecene (which populates a single conformer which is over 2 $\mathrm{kcal} \mathrm{mol}^{-1}$ more stable than any other conformer $)^{50}$ so the correct identification of the rate-determining step depends on finding a competitive initial $\eta^{2}$-complex. A number of complexes were examined, but the lowest energy cyclodecene conformer lies within $\pm 0.5 \mathrm{kcal} \mathrm{mol}^{-1}$ of the lowest energy $\eta^{2}$-complex we could find. An attempt was also made to find turned (type c) conformers on the cyclodecene pathway, but these optimised to the aligned reactive (type b) conformers.

\section{Conformation of the metallocyclobutane (C)}

The metallocyclobutanes have long been viewed as the pivotal species on the RCM energy surface. ${ }^{51}$ To build metallocyclobutane templates to be used to construct a starting structure for each $\mathrm{C}_{x}$ ligand, the heterocyclic carbene and chloride ligands were first frozen and Monte Carlo MM conformational searching was carried out; restricted searches were carried out because the parameterisation of ruthenium in $\mathrm{MM}$ is inadequate. We shall subsequently refer to this as the Monte Carlo/frozen atoms method. Distinct structures were then optimised (without constraints) at the B3LYP/LACVP* and M06-L/LACVP* levels.

The sets of metallocyclobutane conformers were checked against the cycloalkene conformer sets (vide infra), and when there were important absences, the appropriate metallocyclobutane complexes were constructed manually on the template. Both diastereoisomeric complexes were constructed for cycloalkene conformers which lacked mirror plane symmetry. The use of different approaches here is intended to avoid bias and increase the chances of locating unexpected but important conformers.

Metallocyclobutanes were found to match all the 5- and 6membered $\eta^{2}$-complexes and the order of free energy differences between them was preserved. The lower stability of the cyclohexene-forming half-chair $\left(+2.1 \mathrm{kcal} \mathrm{mol}^{-1}\right)$ at the metallocy- clobutane stage is surprising. The boat conformer is more twisted to minimise the number of eclipsed bonds, but retains the close $\mathrm{H} \cdots \mathrm{H}$ contact between 1,4-hydrogen atoms ( $2.27 \AA)$ expected for the hydrocarbon itself (Fig. 7a). This means that the half-chair metallocyclobutane must be significantly destabilised, and there is a new eclipsing interaction, and an additional close $\mathrm{H} \cdots \mathrm{H}$ contact (of $2.19 \AA$ ) which may be responsible. The alternative half-chair is still higher in energy (by $4.4 \mathrm{kcal} \mathrm{mol}^{-1}$ ). These results suggest that all the metallocyclobutane complexes en route to cyclohexene are significantly destabilised by non-bonded interactions.
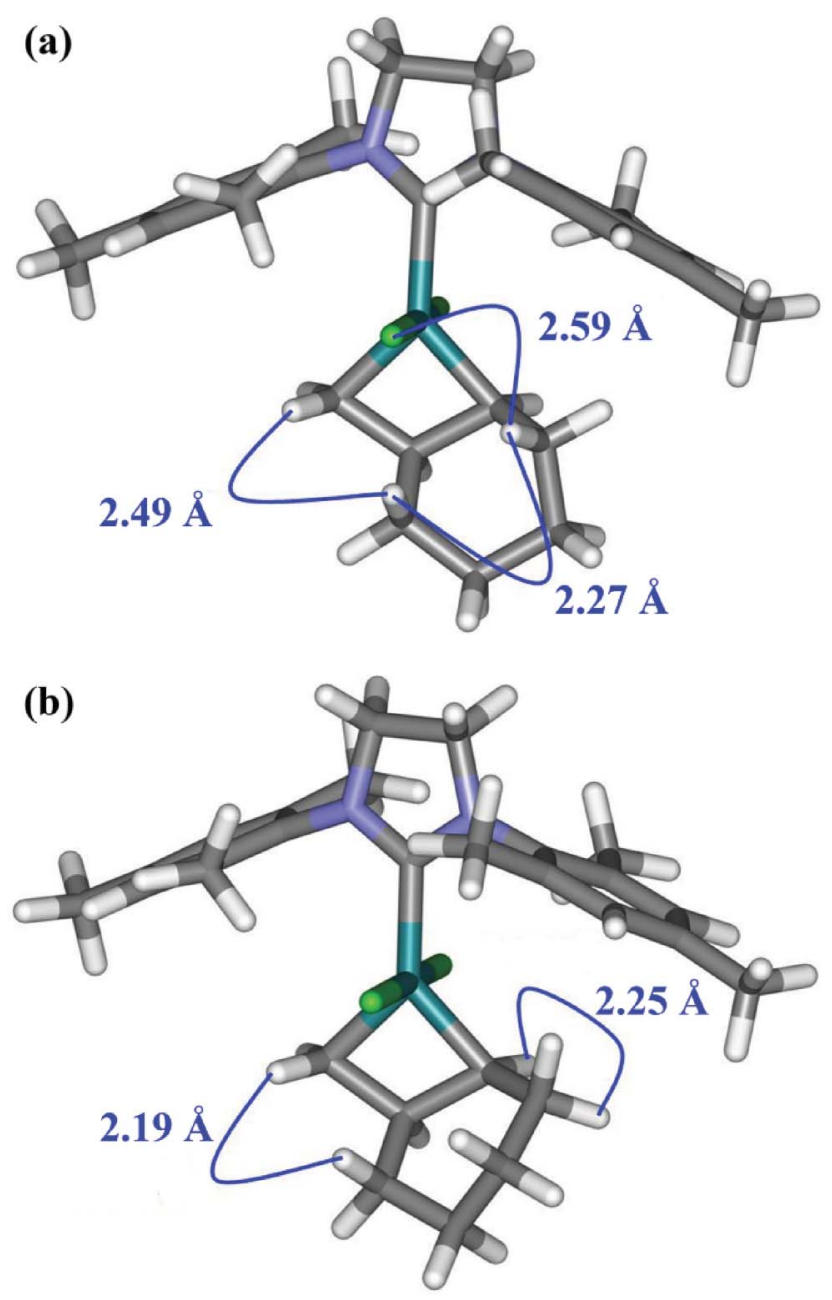

Fig. 7 (a) Twisted-boat and (b) half chair metallocyclobutane conformers (M06-L/B2) showing inter-atomic close contacts.

Cycloheptene is reported to occupy chair $(0.00)$, twist $(+1.1$ kcal $\left.\mathrm{mol}^{-1}\right)$ and boat $\left(+3.8 \mathrm{kcal} \mathrm{mol}^{-1}\right)$ conformers according to computational (the MP2/6-31G* relative free energies are given in parentheses) $)^{52}$ and $\mathrm{NMR}^{53}$ studies. In our M06-L/6$31 \mathrm{G}^{*} / / \mathrm{MMFF} 4$ calculations, we found chair, twist-chair and twist-boat conformers with relative free energies of $+1.0 \mathrm{kcal} \mathrm{mol}^{-1}$ for the twist-chair and $+2.7 \mathrm{kcal} \mathrm{mol}^{-1}$ for the twist-boat, but the symmetrical boat conformer was not a minimum at this level of theory. ${ }^{54}$

Monte Carlo conformational searching for the metallocyclobutane using the frozen atom approach yielded symmetrical boat, symmetrical chair and one twist-chair metallocyclobutane 
complex, but the twist boat conformer was not found. The other (diastereoisomeric) twist-chair metallocyclobutane complex was constructed manually and optimised (B3LYP/LACVP*). We found that the electronic energy of the chair conformer was $3.2 \mathrm{kcal} \mathrm{mol}^{-1}$ lower than the boat, with the twist conformers decisively higher at +8.4 and $+7.2 \mathrm{kcal} \mathrm{mol}^{-1}$. The energies of the complex converged, but followed the same order when the M06$\mathrm{L}$ functional was used (LACVP* basis), the relative electronic energies being chair $(0.00)$, boat $\left(+1.6 \mathrm{kcal} \mathrm{mol}^{-1}\right)$ and twist $(+5.2$ and $\left.+6.8 \mathrm{kcal} \mathrm{mol}^{-1}\right)$. The identity of the lowest energy conformer was confirmed with the larger basis (M06-L/B2) revealing an advantage of $2.0 \mathrm{kcal} \mathrm{mol}^{-1}$ for the chair so the B3LYP functional has identified the lowest energy conformer correctly, which is also the one expected. The relatively high energies of the twisted conformations may be due to short $(<2.7 \AA) \mathrm{C}-\mathrm{H} \cdots \mathrm{Cl}-\mathrm{Ru}$ contacts. The larger ring systems afforded further opportunities to test the ability of the B3LYP functional to order conformers correctly. The conformations available to the cyclooctyl and cyclononyl series were explored carefully because these systems present challenges in synthetic chemistry and mark points at which step changes in efficiency occur. Whereas there are many examples of successful closures of cyclooctenes, ${ }^{55-58}$ with even annulations proceeding smoothly when the systems are suitably "geared", $59-63$ there are fewer reports of successful cyclononene closures $^{64-66}$ and we were anxious to represent any major differences between the systems accurately. ${ }^{67-69}$

Boat-chair type conformers are favoured for ciscyclooctenes, ${ }^{70-72}$ and we have not found other documented conformers. Monte Carlo conformational searching for ciscyclooctene identified the boat-chair as the lowest, and three other conformers. The next lowest $\left(2.1 \mathrm{kcal} \mathrm{mol}^{-1}\right)$ lies between boat-boat and twist-boat conformers (we refer to the nomenclature used for cyclooctane conformers by Eliel). ${ }^{45}$ The third (3.6 kcal $\mathrm{mol}^{-1}$ ) resembles a twist-chair-chair conformation while the fourth $\left(6.2 \mathrm{kcal} \mathrm{mol}^{-1}\right)$ is closest to a chair-chair conformation.

All four conformers are chiral so diastereoisomeric pairs of metallocyclobutane complexes must be explored, and thus eight product complexes were built using the template (they were not all found by the Monte Carlo search using the frozen atom approach) based on the optimised cyclooctene structures. These complexes were optimised (B3LYP/LACVP*) and, as expected, the boatchair conformers were the lowest energy in the set, with all the other conformer energies following the same order as those of the uncomplexed cyclooctene.

After minimisation, the two highest energy cyclooctene conformers were not represented amongst the metallocyclobutanes. This may be a consequence of the presence of two additional $\mathrm{sp}^{3}$ centres in the metallocyclobutane complexes, since their replacement of $\mathrm{sp}^{2}$ centres will cause additional transannular or van der Waals strain. Cyclooctenes constructed from the highest energy metallocyclobutane conformations (by ablation of the atoms dervied from the complex and installation of an alkene) minimised to the higher energy cyclooctenes consistent with this view. To check the effectiveness of the more economical B3LYP conformer screening method, we also optimised all eight metallocyclobutanes (M06-L/LACVP*) and calculated single point energies (M06L/LACVP*) at the B3LYP geometries; Table 2 summarises the results obtained using the different methods. There are two diastereoisomeric complexes for each cyclooctene conformer.
Table 2 Relative electronic energies $\left(\mathrm{kcal} \mathrm{mol}^{-1}\right)$ for optimised geometries using the different methods. Each cyclooctene conformer has a pair of diastereoisomeric complexes

\begin{tabular}{llll}
\hline Cyclooctene Conformer $\left(\mathrm{G}_{\text {rel }}\right)^{a}$ & Method 1 $^{b}$ & Method 2 $^{b}$ & Method 3 $^{b}$ \\
\hline Boat-chair & 0.00 & 0.03 & 0.00 \\
Boat-boat/twist-boat & 0.55 & 0.00 & 0.37 \\
& 4.86 & 3.61 & 4.68 \\
Twist-chair-chair & 6.72 & 4.92 & 4.79 \\
& 4.93 & 4.40 & 5.27 \\
Chair-chair & 5.35 & 4.66 & 5.66 \\
& 10.80 & 8.06 & 8.56 \\
& 10.51 & 9.33 & 9.78
\end{tabular}

${ }^{a}$ M06-L/6-31G*//MMFF94. ${ }^{b}$ Method 1: Optimised geometry (B3LYP/LACVP*). Method 2: Single points (M06-L/LACVP*//B3LYP/ LACVP*). Method 3: Optimised geometry (M06-L/LACVP*).

The electronic energies of the M06-L optimized structures follow the same order as the cyclooctene free energies, and the M06L/LACVP*//B3LYP/LACVP* and B3LYP/LACVP* electronic energies follow approximately the same order as the cyclooctene free energies. As in the cycloheptene case, the differences between the conformer energies increase at the metallocyclobutane stage. Overall, these results suggest strongly that the screening process that we have undertaken with the B3LYP functional allows the reliable identification of low energy conformers. We note that only the boat-chair species was optimised using the large B2 basis. We therefore pursued a unique single starting $\eta^{2}$-complex based on the boat-chair conformer, corresponding to the lowest energy metallocyclobutane. The strategy for the product $\eta^{2}$-complexes will be discussed later in this paper.

Cyclononene partitions between two conformers at low temperature according to Noe and co-workers, who used $a b$ initio (HF/6-311G*) calculations and low temperature NMR methods to identify the main species. ${ }^{73}$ We generated a set of six cycloalkene conformers within $2 \mathrm{kcal} \mathrm{mol}^{-1}$ of each other (M06-L/631G*//MMFF94), and used these, and the Monte Carlo/frozen atoms method, to construct the complexes of interest on the metallocyclobutane template. The presence of conformers of very similar energy was likely to provide a sterner test of the B3LYP screening method. One of the conformers has mirror plane symmetry but the rest are chiral so eleven complexes were built and optimised. We found two groups of metallocyclobutanes; five conformers lay within $1 \mathrm{kcal} \mathrm{mol}^{-1}$, with the other six conformers $2.5 \mathrm{kcal} \mathrm{mol}^{-1}$ or more higher than the lowest energy species. Though the lowest energy conformer from the B3LYP screen is no longer the most stable species at the M06-L/LACVP* level, it lies within $0.5 \mathrm{kcal} \mathrm{mol}^{-1}$ of the most stable complex, and does match the most stable cyclononene conformation. We can therefore safely use this conformer to explore the starting $\eta^{2}$-complex because there is no alternative species at significantly lower energy. The geometries of the product complexes will be discussed later in the manuscript.

There is very strong linkage between the most favourable metallocyclobutane and the most stable cycloalkene conformer, particularly for the seven to nine membered rings. This is an important observation which potentially can be used to guide investigations of much more complex systems. It suggests that the knowledge gained from a thorough investigation of product 
cycloalkene geometries can be transferred directly and informatively to the more computationally-demanding complexes.

Conformational searching was carried out for the 10-membered metallocyclobutane but none of the species found were lower in energy than the initial $\eta^{2}$-complex; we therefore worked with the conformation corresponding to the lowest energy $Z$-cyclodecene.

\section{Conformation of the cycloalkene complex (D)}

For the product cycloalkenes, the $\eta^{2}$-complexes were built from the cycloalkene conformer sets using either the B3LYP or M06$\mathrm{L}$ templates. Both diastereoisomeric complexes were constructed for cycloalkene conformers which lacked mirror plane symmetry. The structures were optimised at the B3LYP/LACVP*, M06L/LACVP* or M06-L/B2 levels. One general observation which emerged is that complexation of the cycloalkene to the ruthenium methylidene does not change the order of conformer energies, the lowest energy cycloalkene conformer being the same with or without complexation to ruthenium, at least for the electronic energies. Once again, the B3LYP functional appears to order complex energies correctly.

\section{The potential energy surface}

The metallocyclobutane is of similar, or of lower energy, than the initial $\eta^{2}$-complex, for all the systems studied, except for the one that leads to cyclodecene (Table 1). We have therefore focused on the metallocyclobutane and product $\eta^{2}$-complexes in the discussion that follows, and calculated only transition structures that lie between the lowest energy metallocyclobutane and product $\eta^{2}$-complexes. The correspondence between orders of cycloalkene, cycloalkene $\eta^{2}$-complex and metallocyclobutane energies suggests very strongly that with one exception (the 6membered ring), the product conformation may also be a reliable indicator of conformation for the initial $\eta^{2}$-complex. We have therefore confined our attention to single initial $\eta^{2}$-complex conformations that match the product $\eta^{2}$-complex.

\section{Structural features of the potential energy surface}

We first comment on the transition structures we have identified for the various steps of the RCM reactions. Transition structures were difficult to find between the carbenes and the initial $\eta^{2}$-complexes because of the shallow energy surfaces, though we succeeded in three cases. Fig. 8a shows the transition structure found between the $14 \mathrm{e}$ and $\eta^{2}$-complex for cyclopentene formation.

The alkene carbon $\cdots \mathrm{Ru}$ distances are close to $4 \AA$ and the alkene $\mathrm{C}-\mathrm{C}$ bond is skewed by $45^{\circ}$ away from the $\eta^{2}$-complex alignment. There has been minimal motion of the $\mathrm{Ru}=\mathrm{CH}$ alkylidene bond at the barrier. Inspection of the imaginary frequency shows that the transition structure involves the formation of $\mathrm{Ru}-\mathrm{C}$ bonds, rather than a flexing motion of the tether, and we note that this transition structures connects to a coiled conformation of A, rather than the extended chain structure. We were not able to find transition structures for cycloalkene release from the methylidene complexes. Transition structures for metallocyclobutane formation and fragmentation were easier to find. We looked for single structures that linked the conformers identified by searching as described in the previous sections; in this way, one productive complex can be tracked smoothly throughout
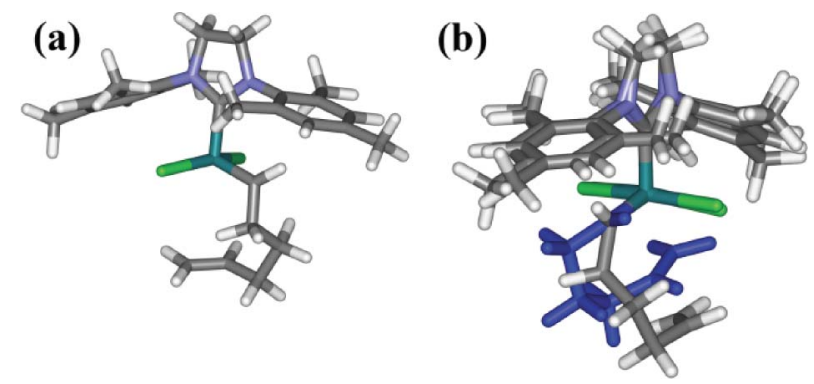

Fig. 8 (a) Transition structure found between the $14 \mathrm{e}$ and $\eta^{2}$-complex for cyclopentene formation and (b) transition structure $/ \eta^{2}$-complex (blue) overlay showing the change in alkylidene geometry and progression of alkene into $\eta^{2}$-coordination.

the entire reaction sequence. The transition structures for metallocyclobutane fragmentation are consistently the highest points on the energy surface and are therefore of critical importance for an appreciation of the barriers to turnover (vide infra). Our searching on the cyclodecene surface gave us an opportunity to investigate a number of such transition structures but it was reassuring to find that the lowest energy barrier corresponded to the lowest energy $Z$-cyclodecene conformer.

We now employ the key distance d, shown in Fig. 9 as a function of ring size at various points on the energy surface, to highlight the structural changes during the reaction. In the metallocyclobutanes, $\mathrm{d}$ was effectively constant varying only between 1.60 and $1.65 \AA$. The transition structures were also very similar, with modest variation in d between 2.13 and $2.23 \AA$ for metallocyclobutane formation, and between 2.19 and $2.31 \AA$ for metallocyclobutane fragmentation. The variation in $d$ in the $\eta^{2}$ complexes was greater, particularly in the initial complexes, where there appeared to be two distinct groups of ring systems, with the smaller rings allowing closer approach of the reaction carbon centres and a step change in d between 6 and 7 membered rings.
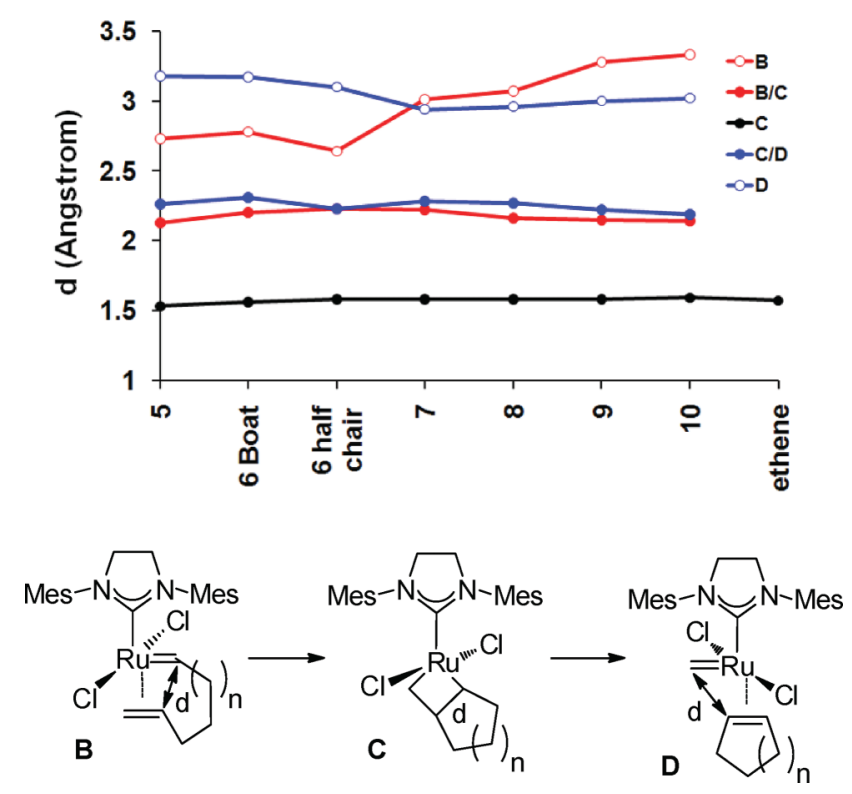

Fig. 9 Variation in distance $\mathrm{d}$ as ring size varies for the key complexes (B-D) and transition states (B/C, C/D) (M06-L/B2 optimised structures). 
Potentially, the large value of $\mathrm{d}$ in $\mathbf{B}$ is advantageous as it may reduce the development of transannular strain at this stage, though the penalty for this will be weaker complexation. The progression from the $\eta^{2}$-complex to the metallocyclobutanation transition state becomes increasingly expensive as the change in $\mathrm{d}$ becomes larger.

The D-complexes occupy a much tighter range of geometries than the initial $\eta^{2}$-complexes with $d$ at its greatest for the 5 and 6-membered rings. The plane which includes the alkene and allylic carbons is tilted away from the alkylidene plane, presumably to ease steric crowding arising from the presence of allylic protons.

The metallocyclobutanes and the transition states for their fragmentation are structurally very similar. There is also a close relationship between the value of $d$ in the product $\eta^{2}$ complex $\mathbf{D}$ and in the transition structure for metallocyclobutane fragmentation, the two lines in Fig. 9 mirroring each other.

It is of interest to examine the changes in the ligand geometry during the RCM reaction. Fig. 10 shows the three main reaction complexes (M06-L/B2) on the pathway for cyclopentene formation in overlay to expose the motion of the ligand; the NHC ligand tilts and turns during the course of the reaction. The parallel relationship between alkylidene plane and aryl ring can be seen clearly in Fig. 10a (red and green structures); the ligand appears to rock across the top of the complex like a three-position switch, with the metallocyclobutane (blue) in the mid-position, with the NHC ligand disposed more symmetrically over the metallocyclobutane. The turning movement around the $\mathrm{Ru}-\mathrm{C}$ bond to the carbene carbon of the NHC ligand can be seen in Fig. 10b.
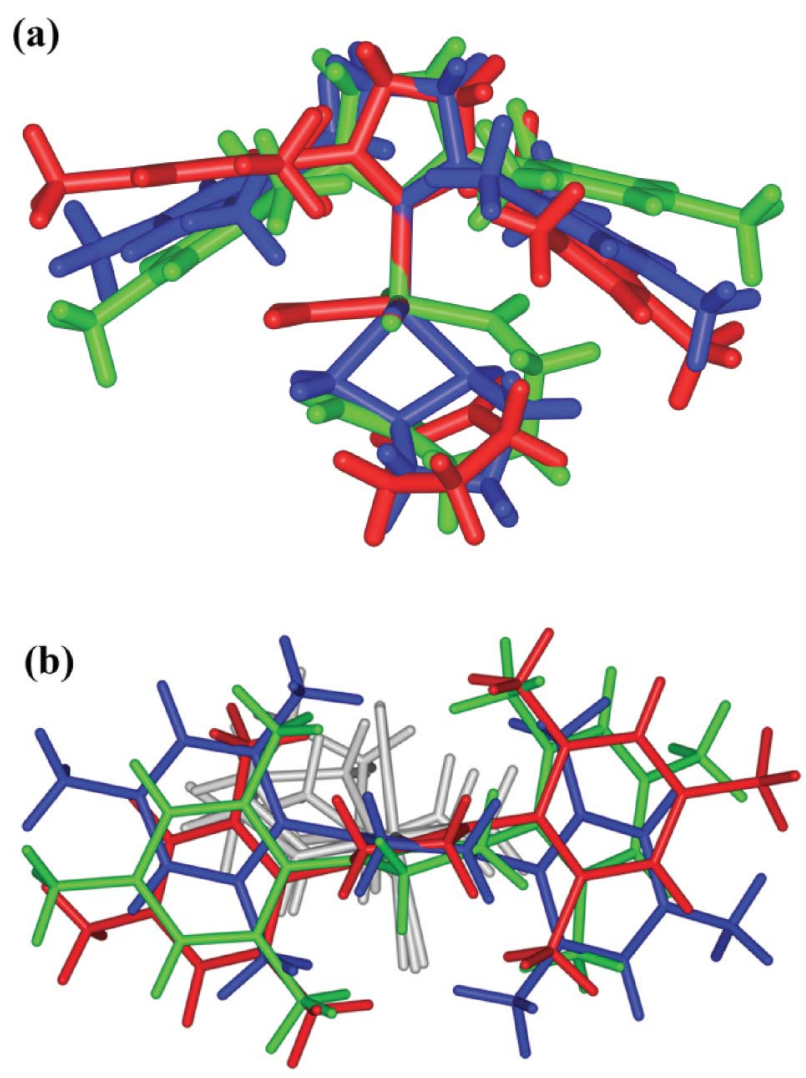

Fig. 10 Overlay of the three main reaction complexes (M06-L optimised structures); starting $\eta^{2}$-complex in green, metallocyclobutane in blue and product $\eta^{2}$-complex in red (a) in profile and (b) from above.
The more acute angle between the planes of the arene rings in the NHC ligand in the M06-L optimised structures shortens certain $\mathrm{C}-\mathrm{H} \cdots \mathrm{C}(\mathrm{Ar})$ contacts by up to $0.5 \AA$ relative to the $\mathrm{B} 3 \mathrm{LYP}$ geometry, without changing the position or conformation of the hydrocarbon tether. The starting boat $\eta^{2}$-complexes en route to cyclohexene are overlaid in Fig. 11a (M06-L red, B3LYP blue); the change in the position of the arene which sits over the alkylidene $(\mathrm{Ru}=\mathrm{C})$ bond is minimal whereas the left-hand arene which is in a very open sector of space changes position. The closest $\mathrm{C}-$ $\mathrm{H} \cdots \mathrm{C}(\mathrm{Ar})$ contacts are very similar in the two complexes in (a).
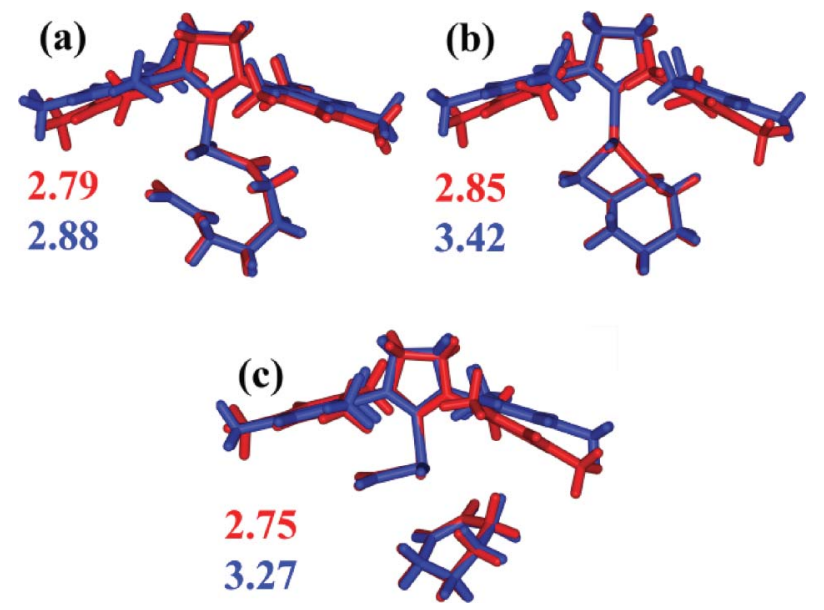

Fig. 11 Overlays of DFT-optimised structures (B2 basis) for (a) $\eta^{2}$-complex (boat), (b) metallocyclobutane (boat) and (c) product $\eta^{2}$-complex (half-chair). M06-L structures are in red, B3LYP structures are in blue and distances are in $\AA$.

Our model calculations, previously described (vide supra), show that these close contacts do result in attractive interactions when the M06-L functional is used. The rocking of the ligand also shortens the $\mathrm{C}-\mathrm{H} \cdots \mathrm{C}(\mathrm{Ar})$ contacts in Fig. 11b and Fig. 11c, relative to the B3LYP structures.

\section{Energetic features of the potential energy surface}

There are clearly expected to be differing entropy contributions to the various stages of the RCM reaction. These have been included within the gas phase rigid-rotor, harmonic oscillator model, with the effect of solvation being taken into account by a continuum model, which yields the solvation free energy. The solvent will clearly modify the entropic changes predicted by the gas phase model, but since the consideration of such effects is beyond the scope of the present paper, it is useful to present the potential energy surface without the gas phase entropy terms, but still retaining the solvation free energies. ${ }^{18}$ Table 3 contains the enthalpy plus solvation free energy changes during the reaction, to be compared to the corresponding total free energy changes given in Table 1.

The difference between the corresponding values gives the entropy contribution. We find that the initial cyclisation from $\mathbf{A}$ to $\mathbf{B}$, bears, as expected, a significant entropy loss, which increases from $12 \mathrm{eu}$ to $23 \mathrm{eu}$ as the ring size increases from 5 to 10 . This corresponds to an entropy loss of 2 eu for each additional C-C bond, which is somewhat smaller than the value of 4 eu suggested by Galli and Mandolini. ${ }^{28}$ For the other steps in the reaction 
Table 3 Energies $\left(\mathrm{kcal} \mathrm{mol}^{-1}\right)$ at the M06-L/B2 level for the full reaction profiles

\begin{tabular}{llllllll}
\hline Ring Size & Diene $+\mathbf{2}$ & $\mathbf{A}$ & $\mathbf{B}$ & $\mathbf{B C}$ & $\mathbf{C}$ & $\mathbf{C D}$ & $\mathbf{D}$ \\
\hline 5 & 0 & -5.01 & -19.94 & -18.61 & -20.27 & -6.97 & -10.28 \\
6 & 0 & -5.20 & -15.66 & -14.77 & -19.83 & -10.51 & -14.03 \\
7 & 0 & -5.36 & -17.43 & -13.76 & -20.26 & -9.75 & -10.92 \\
8 & 0 & -4.93 & -16.05 & -11.73 & -16.78 & -8.33 & -10.20 \\
9 & 0 & -5.26 & -11.23 & -7.93 & -12.85 & -4.10 & -6.89 \\
10 & 0 & -5.00 & -16.20 & -9.82 & -13.82 & -7.72 & -11.54
\end{tabular}

Energies are based on $\mathrm{H}+\Delta G_{\text {solv }}$.

we find that there is no systematic variation in the size of the entropy change with hydrocarbon chain length, but the trends in its magnitude for the different reaction steps are as expected. Conformational reorganisation as the $\eta^{2}$-complex (B) progresses to the metallocyclobutanation transition state is minimal so the free energy change is expected to be dominated by the enthalpic component. For this step, the calculated entropy loss is in the range 3-9 eu. There is a slightly greater entropy gain (4-11 eu) for the formation of the cycloalkene complex (D) from the cyclobutane (C).

Turning to the energy changes during the reaction, the free energy differences between entry to and entry from the RCM cycles not only represent predictions of the thermodynamic changes which control RCM, but also enable the identification of the steps that control turnover. Fig. 12 summarises the data from Table 1 in graphical form.

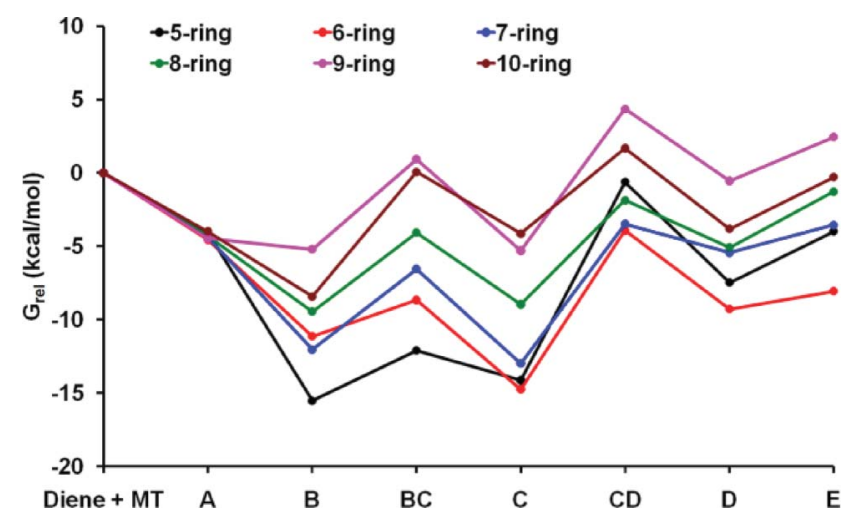

Fig. 12 Free energy profiles for RCM reaction (in $\mathrm{kcal} \mathrm{mol}^{-1}$, M06-L/B2, dichloromethane, $298 \mathrm{~K}$ ).

The reactions fall into four groups. Cyclohexene formation is clearly exceptional, in terms of both $\Delta H$ (Table 3 ) and $\Delta G$ (Table 1) with a very favourable equilibrium constant $\left(\mathrm{K}=8.15 \times 10^{5} \mathrm{M}\right.$ at $298 \mathrm{~K}$ based on $\left.\Delta G=-8.06 \mathrm{kcal} \mathrm{mol}^{-1}\right)$. Except for the largest ring size (10), we see that the step that controls the throughput is metallocyclobutane fragmentation to product $\eta^{2}$-complex. The return of metallocyclobutane through the cycle is a faster reaction but the forward cycle is driven by conversion of diene to form $\mathbf{A}$.

Decomplexation is an important event in turnover. The process was endergonic by $3.0-3.8 \mathrm{kcal} \mathrm{mol}^{-1}$ for the 5 and $8-10$ membered rings, with smaller penalties for the $7\left(1.9 \mathrm{kcal} \mathrm{mol}^{-1}\right)$ and $6(1.2 \mathrm{kcal}$ $\mathrm{mol}^{-1}$ ) ring species. There is no clear correlation between $\Delta G$ and ring strain for this step; the very low degree of pyramidalisation as the alkene complex forms should be noted. Cedeño and
Sniatynsky ${ }^{74}$ have argued that strain relief is maximal when the alkene has pyramidal character before complexation, minimising the conformational reorganisation required. This does not apply to any of the alkenes in the present study. The small energy of complexation for cyclohexene may be due to steric destabilisation of the $\mathbf{D}$ complex. The free energies of the cyclopentene and cyclohexene D complexes are closer than expected based on the strain energy difference (cyclopentene $5.0 \mathrm{kcal} \mathrm{mol}^{-1}$, cyclohexene $\left.0.9 \mathrm{kcal} \mathrm{mol}^{-1}\right)^{75}$ between the cycloalkenes, consistent with this view. All the cyclisations are less favourable when product decomplexation is included in the reaction thermodynamics.

The RCM reactions to form cyclopentene and cycloheptene are very similar according to these calculations, with cyclisation free energies which lie within the limits of accuracy of the calculations $\left( \pm 0.5 \mathrm{kcal} \mathrm{mol}^{-1}\right)$; taking $3.75 \mathrm{kcal} \mathrm{mol}^{-1}$ as an average free energy of cyclisation for these systems affords a $\mathrm{K}$ of $c a .600 \mathrm{M}$ at $298 \mathrm{~K}$. Cyclooctene and cyclodecene fall in the next group; cyclisation free energies are much closer to zero ( $\mathrm{K}$ close to unity). There is a major difference between these systems at the metallocyclobutane complex, with the eightmembered system significantly more stable. The eight-membered ring system appears committed to cyclisation $(\mathrm{K}=8.5)$, but while there is no additional barrier on the pathway to cyclooctene, metallocyclobutane fragmentation is more expensive for the 10membered ring system $(\mathrm{K}=1.58)$. The cyclononene system stands alone with a very unfavourable free energy of cyclisation $(2.45 \mathrm{kcal}$ $\mathrm{mol}^{-1}, \mathrm{~K}=0.016$ ) and still higher barrier to metallocyclobutane fragmentation.

Access to the potential energy surface is controlled by the initiation event which converts the pre-catalyst to active catalyst; strongly bound phosphane dissociates in this step and a number of workers have proposed barriers for this reaction. Grubbs and coworkers used two different approaches to determine experimental values. UV spectrophotometry was used to follow the reaction between pre-catalyst $\mathbf{1 b}$ and ethyl vinyl ether, leading to the irreversible formation of a Fischer carbene complex. ${ }^{76}{ }^{31} \mathrm{P}$ NMR experiments were also used to detect ligand exchange, with the two approaches delivering consistent values for $\Delta G^{\ddagger}(298 \mathrm{~K})$ of the order of $25 \mathrm{kcal} \mathrm{mol}^{-1}$. We have computed the free energy change accompanying the loss of the phosphane from $\mathbf{1 b}$, at the M06$\mathrm{L} / \mathrm{B} 2$ (C-PCM) level, giving a value of $20.8 \mathrm{kcal} \mathrm{mol}^{-1}$, which is close to the experimental estimate. Thus, it would appear that our estimates of the barriers for even the most demanding steps on the cyclisation profiles are relatively low compared to the phosphane binding energy and we find that most of the intermediates on the surfaces lie below the starting alkylidene derived from the pre-catalyst. ${ }^{77}$ If each turnover required the dissociation of the phosphane from the pre-catalyst $\mathbf{1 b}$, this barrier would be the ratedetermining step. However, once the active catalyst has formed, the rate of turnover is controlled by the propagation of $\mathbf{2}$ through the intervening complexes. ${ }^{78,79}$

\section{Conclusions}

In conclusion, we have determined low energy structures for all the intermediates on the RCM pathways and obtained the transition structures that link them. The conformational space around these intermediates has been explored thoroughly and the B3LYP functional has been shown to be effective at ordering 
conformer energies, though the M06-L hybrid functional is used as a source of reliable energies. Metallocyclobutane fragmentation has been identified as the highest barrier within productive RCM sequences. In the case of cyclohexene, the reaction sequence most unexpectedly starts through an unfavourable conformer. The electronic structure calculations rank the cyclisations in the order of efficiency that would be expected from synthetic experimental work, with cyclohexene formation predicted to be orders of magnitude more favourable than any other RCM. Overall, we have provided a robust set of templates for use in analysing more complex systems, and a structural framework upon which a quantitative understanding of RCM can be constructed.

\section{Acknowledgements}

This work was supported by the EPSRC Initiative in Physical Organic Chemistry 2 (EP/G013160/1 and EP/G013020/1) and ORSAS (Studentship to SP).

\section{Notes and references}

1 G. C. Vougioukalakis and R. H. Grubbs, Chem. Rev., 2010, 110, 1746. 2 K. C. Nicolaou, P. G. Bulger and D. Sarlah, Angew. Chem.-Int. Edit., 2005, 44, 4490.

3 A. H. Hoveyda and A. R. Zhugralin, Nature, 2007, 450, 243.

4 M. Bieniek, A. Michrowska, D. L. Usanov and K. Grela, Chem.-Eur. J., 2008, 14, 806.

5 V. Farina, C. Shu, X. Zeng, X. Wei, Z. Han, N. K. Yee and C. H. Senanayake, Org. Process Res. Dev., 2009, 13, 250.

6 C. Shu, X. Z. Zeng, M. H. Hao, X. D. Wei, N. K. Yee, C. A. Busacca, Z. X. Han, V. Farina and C. H. Senanayake, Org. Lett., 2008, 10, 1303.

7 S. Monfette and D. E. Fogg, Chem. Rev., 2009, 109, 3783.

8 H. Y. Wang, W. L. Yim, T. Kluner and J. O. Metzger, Chem.-Eur. J., 2009, 15, 10948.

9 E. F. Van Der Eide, P. E. Romero and W. E. Piers, J. Am. Chem. Soc., 2008, 130, 4485.

10 E. F. Van Der Eide and W. E. Piers, Nat. Chem., 2010, 2, 571.

11 Y. Minenkov, G. Occhipinti and V. R. Jensen, J. Phys. Chem. A, 2009, $113,11833$.

12 A. Correa and L. Cavallo, J. Am. Chem. Soc., 2006, 128, 13352.

13 D. Benitez, E. Tkatchouk and W. A. Goddard, Organometallics, 2009, 28, 2643.

14 C. E. Diesendruck, E. Tzur, A. Ben-Asuly, I. Goldberg, B. F. Straub and N. G. Lemcoff, Inorg. Chem., 2009, 48, 10819.

15 E. Tzur, A. Szadkowska, A. Ben-Asuly, A. Makal, I. Goldberg, K. Wozniak, K. Grela and N. G. Lemcoff, Chem.-Eur. J., 2010, 16, 8726.

16 S. E. Vyboishchikov, M. Buhl and W. Thiel, Chem.-Eur. J., 2002, 8, 3962.

17 S. E. Vyboishchikov and W. Thiel, Chem.-Eur. J., 2005, 11, 3921

18 For a recent study of a single diene catalysed by $1 \mathrm{c}$, see X. SolansMonfort, R. Pleixats and M. Sodupe, Chem.-Eur. J., 2010, 16, 7331.

19 Straub has published a detailed PES for a single case of enyne RCM: see J. J. Lippstreu and B. F. Straub, J. Am. Chem. Soc., 2005, 127, 7444.

20 For a recent review of computational methods applied to organometallic catalysis, see N. Fey, Dalton Transactions, 2010, 39, 296.

21 L. Mitchell, J. A. Parkinson, J. M. Percy and K. Singh, J. Org. Chem., 2008, 73, 2389.

22 J. C. Conrad, M. D. Eelman, J. A. D. Silva, S. Monfette, H. H. Parnas, J. L. Snelgrove and D. E. Fogg, J. Am. Chem. Soc., 2007, 129, 1024.

23 For an example of cycloalkene diastereoisomer equilibration catalysed by $\mathbf{1 b}$, see C. W. Lee and R. H. Grubbs, Org. Lett., 2000, 2, 2145.

24 M. Ulman and R. H. Grubbs, Organometallics, 1998, 17, 2484.

25 K. J. Ivin, Makromol. Chem.-Macromol. Symp., 1991, 42-3, 1.

26 A. J. Kirby, Adv. Phys. Org. Chem., 1980, 17, 183.

27 L. Mandolini, Adv. Phys. Org. Chem., 1986, 22, 1.

28 C. Galli and L. Mandolini, Eur. J. Org. Chem., 2000, 3117.

29 T. A. Halgren, J. Comput. Chem., 1996, 17, 490.

30 Spartan'06, Wavefunction, Irvine, CA, 2006.

31 Spartan'08, Wavefunction, Irvine, CA, 2008.
32 B. F. Straub, Angew. Chem.-Int. Edit., 2005, 44, 5974.

33 S. Pandian, I. H. Hillier, M. A. Vincent, N. A. Burton, I. W. Ashworth, D. J. Nelson, J. M. Percy and G. Rinaudo, Chem. Phys. Lett., 2009, 476, 37.

34 M. Piacenza, I. Hyla-Kryspin and S. Grimme, J. Comput. Chem., 2007, 28, 2275.

35 S. Torker, D. Merki and P. Chen, J. Am. Chem. Soc., 2008, 130, 4808. 36 P. Sliwa and J. Handzlik, Chem. Phys. Lett., 2010, 493, 273.

37 I. C. Stewart, D. Benitez, D. J. O’Leary, E. Tkatchouk, M. W. Day, W. A. Goddard and R. H. Grubbs, J. Am. Chem. Soc., 2009, 131, 1931.

38 Y. Zhao and D. G. Truhlar, J. Chem. Theor. Comput., 2009, 5, 324.

39 For a recent review, see C. J. Cramer and D. G. Truhlar, Phys. Chem. Chem. Phys., 2009, 11, 10757.

40 M. J. Frisch, G. W. Trucks, H. B. Schlegel, G. E. Scuseria, M. A. Robb, J. R. Cheeseman, J. A. Montgomery, T. Vreven, K. N. Kudin, J. C. Burant, J. M. Millam, S. S. Iyengar, J. Tomasi, V. Barone, B. Mennucci, M. Cossi, G. Scalmani, N. Rega, G. A. Petersson, H. Nakatsuji, M. Hada, M. Ehara, K. Toyota, R. Fukuda, J. Hasegawa, M. Ishida, T. Nakajima, Y. Honda, O. Kitao, H. Nakai, M. Klene, X. Li, J. E. Knox, H. P. Hratchian, J. B. Cross, C. Adamo, J. Jaramillo, R. Gomperts, R. E. Stratmann, O. Yazyev, A. J. Austin, R. Cammi, C. Pomelli, J. W. Ochterski, P. Y. Ayala, K. Morokuma, G. A. Voth, P. Salvador, J. J. Dannenberg, V. G. Zakrzewski, S. Dapprich, A. D. Daniels, M. C. Strain, O. Farkas, D. K. Malick, A. D. Rabuck, K. Raghavachari, J. B. Foresman, J. V. Ortiz, Q. Cui, A. G. Baboul, S. Clifford, J. Cioslowski, B. B. Stefanov, G. Liu, A. Liashenko, P. Piskorz, I. Komaromi, R. L. Martin, D. J. Fox, T. Keith, M. A. Al-Laham, C. Y. Peng, A. Nanayakkara, M. Challacombe, P. M. W. Gill, B. Johnson, W. Chen, M. W. Wong, C. Gonzalez and J. A. Pople, Gaussian 03, Revision D.02, Gaussian Inc., Wallingford, CT, 2004.

41 I. W. Ashworth, D. Carboni, I. H. Hillier, D. J. Nelson, J. M. Percy, G. Rinaudo and M. A. Vincent, Chem. Commun., 2010, 46, 7145.

42 D. Andrae, U. Haussermann, M. Dolg, H. Stoll and H. Preuss, Theor. Chim. Acta, 1990, 77, 123.

43 For a recent experimental evaluation of alkylidene transfer free energies with pre-catalyst 1a, see D. R. Lane, C. M. Beavers, M. M. Olmstead and N. E. Schore, Organometallics, 2009, 28, 6789.

44 R. K. Raju, A. Ramraj, I. H. Hillier, M. A. Vincent and N. A. Burton, Phys. Chem. Chem. Phys., 2009, 11, 3411.

45 E. L. Eliel, S. H. Wilen and L. N. Mander, Stereochemistry of Organic Compounds, Wiley-Interscience, New York, 1994.

46 C. Adlhart and P. Chen, J. Am. Chem. Soc., 2004, 126, 3496.

47 For a recent example, see S. J. P'Pool and H. J. Schanz, J. Am. Chem. Soc., 2007, 129, 14200.

48 N. L. Allinger, J. Am. Chem. Soc., 1977, 99, 8127.

49 F. A. L. Anet, D. I. Freedberg, J. W. Storer and K. N. Houk, J. Am. Chem. Soc., 1992, 114, 10969.

50 D. M. Pawar and E. A. Noe, J. Am. Chem. Soc., 1998, 120, 5312.

51 D. Castoldi, L. Caggiano, L. Panigada, O. Sharon, A. M. Costa and C. Gennari, Chem.-Eur. J., 2005, 12, 51.

52 M. K. Leong, V. S. Mastryukov and J. E. Boggs, J. Mol. Struct., 1998, $445,149$.

53 E. S. Glazer, C. Ganter, J. D. Roberts and R. Knorr, J. Am. Chem. Soc., 1972, 94, 6026

54 L. I. Ermolaeva, V. S. Mastryukov, N. L. Allinger and A. Almenningen, J. Mol. Struct., 1989, 196, 151.

55 J. S. Clark, Chem. Commun., 2006, 3571.

56 A. Michaut and J. Rodriguez, Angew. Chem.-Int. Edit., 2006, 45, 5740.

57 J. A. L. Miles, L. Mitchell, J. M. Percy, K. Singh and E. Uneyama, J. Org. Chem., 2007, 72, 12.

58 I. W. Ashworth, J. A. L. Miles, D. J. Nelson, J. M. Percy and K. Singh, Tetrahedron, 2009, 65, 9637.

59 M. T. Crimmins, K. A. Emmitte and A. L. Choy, Tetrahedron, 2002, $\mathbf{5 8}, 1817$.

60 M. T. Crimmins and E. A. Tabet, J. Am. Chem. Soc., 2000, 122, 5473.

61 K. Fujiwara, N. Kawamura, H. Kawai and T. Suzuki, Tetrahedron Lett, 2009, 50, 1236

62 K. Fujiwara, A. Goto, D. Sato, H. Kawal and T. Suzuki, Tetrahedron Lett, 2005, 46, 3465.

63 S. Monfette and D. E. Fogg, in Green Metathesis Chemistry: Great Challenges in Synthesis, Catalysis and Nanotechnology, ed. V. Dragutan, A. Demoncean, I. Dragutan and E. S. Finkelshtein, 2010, pp. 129.

64 M. T. Crimmins and A. L. Choy, J. Am. Chem. Soc., 1999, 121, 5653. 65 S. V. Pansare and V. A. Adsool, Org. Lett., 2006, 8, 5897. 
66 For an unsuccessful nine-membered ring closure, see L. A. Paquette, S. Dong and G. D. Parker, J. Org. Chem., 2007, 72, 7135.

67 For recent ten-membered ring closures, see P. R. Krishna and T. J. Rao, Tetrahedron Lett, 2010, 51, 4017.

68 P. R. Krishna and T. J. Rao, Org. Biomol. Chem., 2010, 8, 3130.

69 K. Tsuboi, T. Nakamura, T. Suzuki, A. Nakazaki and S. Kobayashi, Tetrahedron Lett, 2010, 51, 1876.

70 K. L. Servis and E. A. Noe, J. Am. Chem. Soc., 1973, 95, 171.

71 V. S. Mastryukov, K. H. Chen and N. L. Allinger, J. Phys. Chem. A, 2001, 105, 8562.

72 G. A. Griffith, J. M. Percy, S. Pintat, C. A. Smith, N. Spencer and E. Uneyama, Org. Biomol. Chem., 2005, 3, 2701.
73 D. M. Pawar, S. D. Miggins, S. V. Smith and E. A. Noe, J. Org. Chem., 1999, 64, 2418.

74 D. L. Cedeno and R. Sniatynsky, Organometallics, 2005, 24, 3882.

75 H. A. Skinner and G. Pilcher, Quart. Rev., 1963, 17, 25.

76 M. S. Sanford, J. A. Love and R. H. Grubbs, J. Am. Chem. Soc., 2001, 123, 6543.

77 D. Benitez, E. Tkatchouk and W. A. Goddard, Chem. Commun., 2008, 6194.

78 For recent detailed studies of the initiation behaviour of $1 \mathrm{c}$, see $\mathrm{T}$. Vorfalt, K. J. Wannowius, V. Thiel and H. Plenio, Chem.-Eur. J., 2010, 16, 12312.

79 T. Vorfalt, K. J. Wannowius and H. Plenio, Angew. Chem.-Int. Edit., 2010, 49, 5533. 